\title{
Recommendation Systems in Education: A review of Recommendation Mechanisms in E-learning Environments*
}

\author{
Paola Andrea Otero Cano** \\ Edgar Camilo Pedraza Alarcón ${ }^{* * *}$
}

Received: 7/10/2019 • Approved: 19/06/2020

https://doi.org/10.22395/rium.v20n38a9

\begin{abstract}
In recent years, new trends and methodologies have emerged that greatly favor the education sector. E-learning as an alternative to regular teaching and learning processes has transformed the educational dynamics thanks to the inclusion of MOOCs, personal learning environments, allowing the educational process to be carried out at a personalized level where the focus is on learning styles and the profile of the student. This article presents a review of current works around machine learning mechanisms to make recommendations in the educational environment, where it is found that besides the discovery of the student's learning style, it is important to know their level of knowledge and learning speed, in addition to the tools used by the student to carry out their studies. Finally, the opportunity for implementation and research of these issues in Colombia is highlighted.
\end{abstract}

Keywords: education; e-learning; environments; learning styles; machine learning; MOOC.

* This research was possible hanks to the technical support from the Creatic Technological Development Center and the financial cooperation of the University of Cauca as operator of the Young Researcher initiative.

** Electronics and Telecommunications Engineer from the University of Cauca, Technical Specialist in the Development of Applications for mobile devices, MSc (c) with emphasis on systems and computing, data analyst and researcher in the technology and innovation unit of the CreaTIC Technological Development Center. Orcid: Email: andrea.otero@clustercreatic.com. https://orcid.org/0000-0001-5834-7953.

*** MSc in ICT Management from the Ramon Llull University of Barcelona, Electronics and Telecommunications Engineer from the University of Cauca, leads the Technology and Innovation Unit of the Creatic Development Center. Email: camilo.pedraza@clustercreatic.com. Orcid: https://orcid.org/0000-0002-4582-2425. 


\title{
Sistemas de recomendación en educación: una reseña de los mecanismos de recomendación en entornos de aprendizaje virtual (E-learning)
}

\begin{abstract}
Resumen
Recientemente, han emergido nuevas tendencias y metodologías que han favorecido enormemente al sector educativo. El e-learning como alternativa a los procesos de enseñanza y aprendizaje regulares ha transformado las dinámicas educativas debido a la inclusión de los MOOC, entornos personales de aprendizaje, permitiendo que el proceso educativo sea llevado a cabo en un nivel personalizado en donde el foco esté puesto en los estilos de aprendizaje y el perfil del estudiante. Este artículo presenta una revisión de trabajos actuales alrededor de mecanismos de aprendizaje de máquina para hacer recomendaciones en el entorno educativo, en donde se encuentra que, aparte del descubrimiento del estilo de aprendizaje del estudiante, es importante conocer su nivel de conocimiento y su velocidad de aprendizaje, así como las herramientas usadas por el estudiante para llevar a cabo sus estudios. Finalmente, se hace énfasis en la oportunidad de implementar y seguir investigando estas cuestiones en Colombia.
\end{abstract}

Palabras clave: educación; aprendizaje virtual; entornos; estilos de aprendizaje; aprendizaje de máquina; MOOC. 


\section{INTRODUCTION}

With the emergence of Information and Communication Technologies (ICT) a richer and more diverse access to any type of information was generated; richer regarding the amount of information that currently exists on the Internet or in specific data centers, and diverse, by the different tools through which it can be accessed (tablets, smartphones, computers, e-books and smart-watches) [1].

In this sense, the education sector is affected by these advancements, which makes it begin a migration and transformation of its traditional teaching and learning processes, breaking down barriers that existed in the past, such as the geographical and/ or temporal limitations of the traditional scheme [2]. According to this, new trends such as distance education, online educational platforms, MOOC and e-learning become a support to offer quality education in different ways.

This article presents the bibliographic review of current works about automatic learning mechanisms which is framed within a research project titled "Adaptive platform based on automatic learning mechanisms for the appropriation of technologies in students of high school of Popayan city".

\section{DEFINITION OF THE PROBLEM}

Considering the premise that the emergence of new technologies has transformed and impacted society in different sectors [3], and especially the educational one and where the technological influence has changed the teaching paradigm, taking teachers to diversify their pedagogical practices and processes in function of information and communication technologies (ICT) so that they are more effective and efficient [4], models, systems, platforms and applications are developed to include technology in classrooms in order to facilitate learning for students. However, these systems should not only try to offer a list of educational resources independent of the tastes, preferences and characteristics of the users, but on the contrary, they should improve the educational experience. For this purpose, automatic learning mechanisms have been used to appropriately identify the information presented to each of the students and thus constantly improve the systems based on their experience, which helps to make better decisions [5].

Accordingly, there are still shortcomings in how educational resources are provided. Students receive information that is not consistent with their individual characteristics, learning styles and preferences; In addition, it does not take into account the technological resources or tools available in its environment, such as a computer, tablet, smartphone, Smart TV, devices to develop IoT (internet of things) projects, among others. In this sense, there is evidence of the need to have a system, platform 
and/or application that facilitates educational resources, learning from the students' experience to make decisions aligned with their learning profile.

\section{METHODOLOGY AND RESULTS}

For the review of recommendation mechanisms presented in this paper, a search is made for works related to the development of an educational platform based on automatic learning mechanisms. In the first place, the keywords ro review were selected both in spanish an english. The keywords were: adaptive learning platform, recommender system, education/educative, adaptive learning, machine learning, learning style, E-learning, virtual learning environment.

Then, the search for related literature was made, looking for platforms-systems related with recommendation/adaptive focused on the educational/learning/machine learning fields. The search flow is represented in figure 1 .

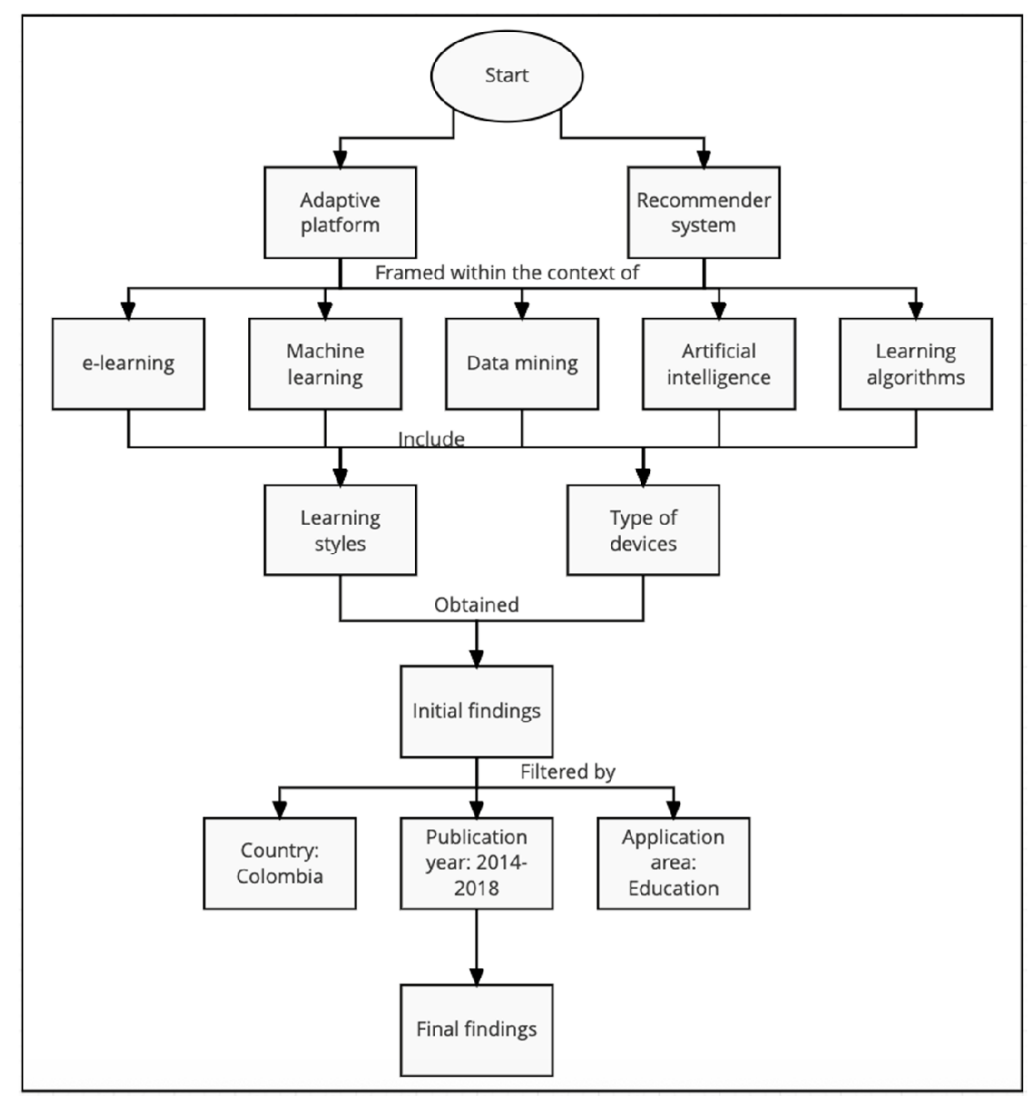

Figure 1. Search flow.

Source: own elaboration 
In this first search, 21,444 results were obtained from 1933 to 2019. An analysis of the results between 2001 and 2018 shows a trend in the growth of work focused on developing recommendation systems in the context of e-learning, as can be seen in figure 2 .

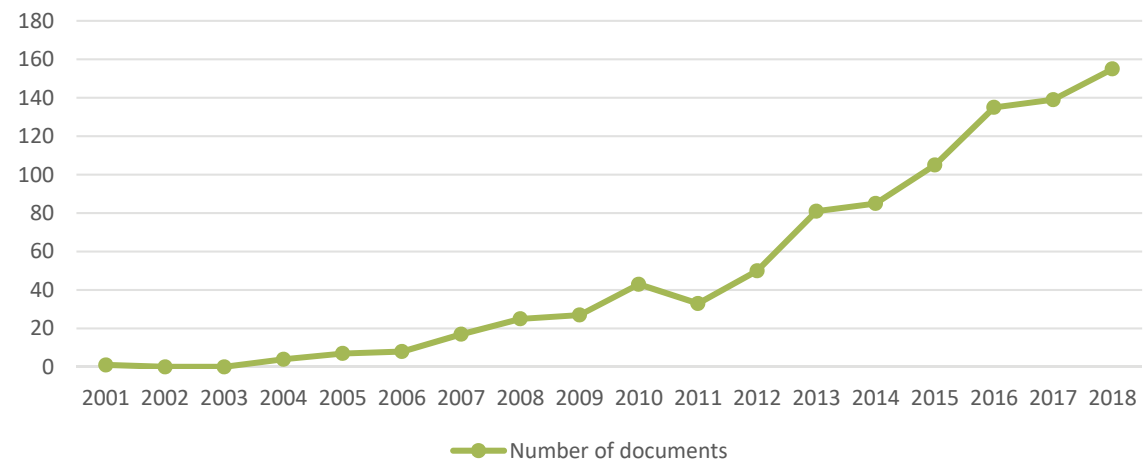

Figure 2. Documents by year.

Source: own elaboration

Filtering the search since 2015, 6,978 results were obtained and only 47 in Colombia. Although within the results of the search was emphasized learning and education, these were inclined towards platforms and applications in sectors like commerce, business and medicine. In this sense, a search equation is made that limits the results and are more specific for the educational sector. For this purpose, a search for an "adaptive platform" or "recommendation system" for "education" that integrates "E-learning" or "artificial intelligence" technologies is made and that considers the "learning styles" and the "devices" of the users. The search excludes medical, economics, physics, mathematics, psychology and arts sectors, and is limited to obtaining results since 2015. In this way, 431 results were obtained and only 18 in Colombia, as can be seen in figure 3 .
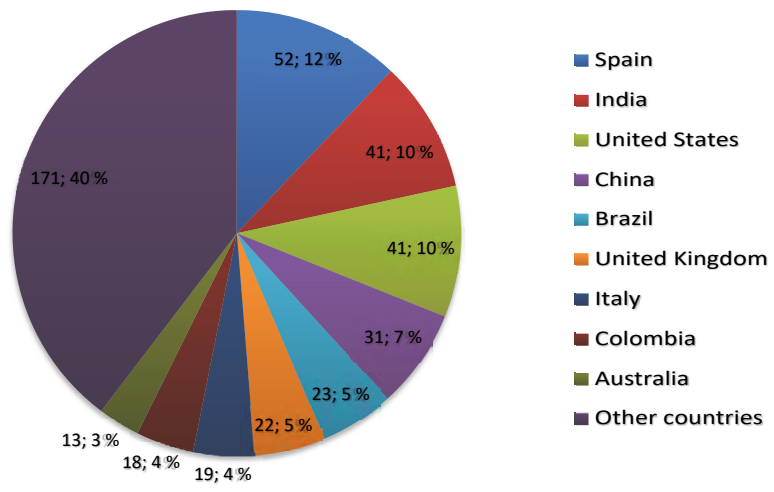

Figure 3. Documents by country.

Source: Own elaboration 
The search equation is presented in Table 1.

Table 1. Search equation

\begin{tabular}{|c|}
\hline Search Equation \\
\hline 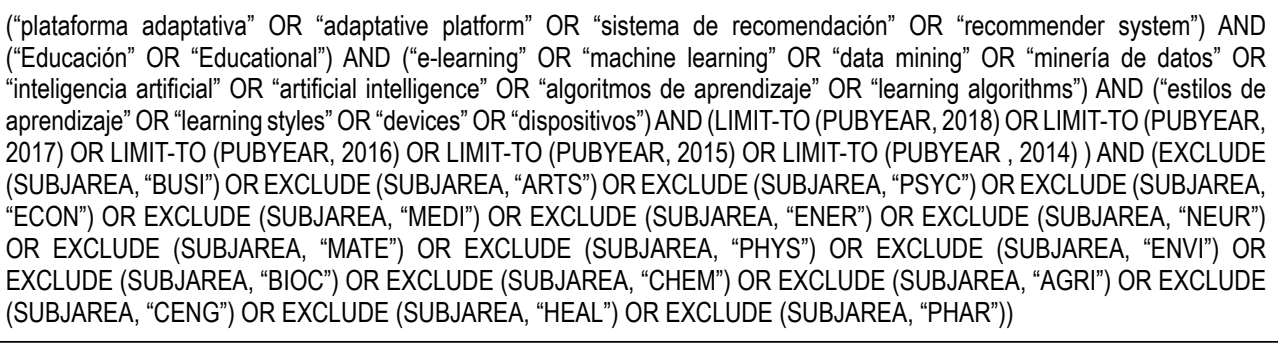 \\
\hline
\end{tabular}

Source: Own elaboration

According to the results, the articles are analyzed with the following criteria: 1) Strictly linked with education, 2) Representation of a current state or summary of the technologies used in other related work, 3) High value proposal or solution for the development of the research project (regardless of the sector where it is applied). In this sense, the results are grouped into the following categories: I) Works that improve the student-educator relationship, II) Works that establish monitoring strategies to evaluate the learning practices. III) Works that evaluate techniques, algorithms and models to make recommendations in the teaching and learning processes.

\section{Student-educator relationship}

The study in [6], proposes a tool to link students with supervisors according to the experience, maximum workload and interest of the supervisor and the preferences of the students. In the article [7], data mining techniques are employed to examine unique patterns between the use of technology and experiences related to student learning, through this, the practice carried out by the teachers and the design of their learning route are reported.

\section{Monitoring of learning practices}

References [8] and [9] make recommendations based on information obtained through interactions or social networks, from which the student's profile and learning style are extracted. In [10] they extract metadata from the visited OCW websites that commuted with the learning styles given by Felder Silverman's theory suggesting the learning recommendations.

The authors of [11-13] propose a new approach to e-learning systems by integrating fuzzy logic models, the big data framework and the semantic web to make content 
adaptation to LMS platforms more effective. In [14] and [15] the authors developed a recommendations platform using artificial intelligence that can be adapted and customized for different use cases, taking into account the ecosystem and the daily life of the user.

In [16], the author presents a system of recommendations based on affective computing and collaborative filtering techniques. The authors of [17] and [18] present recommendation systems that are based on students' needs and level of knowledge.

\section{Evaluation of techniques, algorithms and models}

The authors of [19] evaluate 12 popular automatic learning algorithms, including classification and regression trees, artificial neural networks and algorithms to determine similarity. In [20] the performance of the Naïve Bayes tree is evaluated to determine students' learning styles. The authors of [21-23] present concepts and trends about e-learning and the use of data mining in education, concluding that it is a basic need to incorporate the learning styles and needs of students into the learning pathways designed by educators, also proposing an approach where MOOCs can be adapted and customized to the characteristics of students along with their learning pace.

Based on the results obtained in the search, a mental map is elaborated with the most outstanding keywords within it. According to the above, there is a trend in searches for recommendation systems in the context of e-learning, supervised learning algorithms, machine learning and its application in education. The mental map is presented in figure 4 .

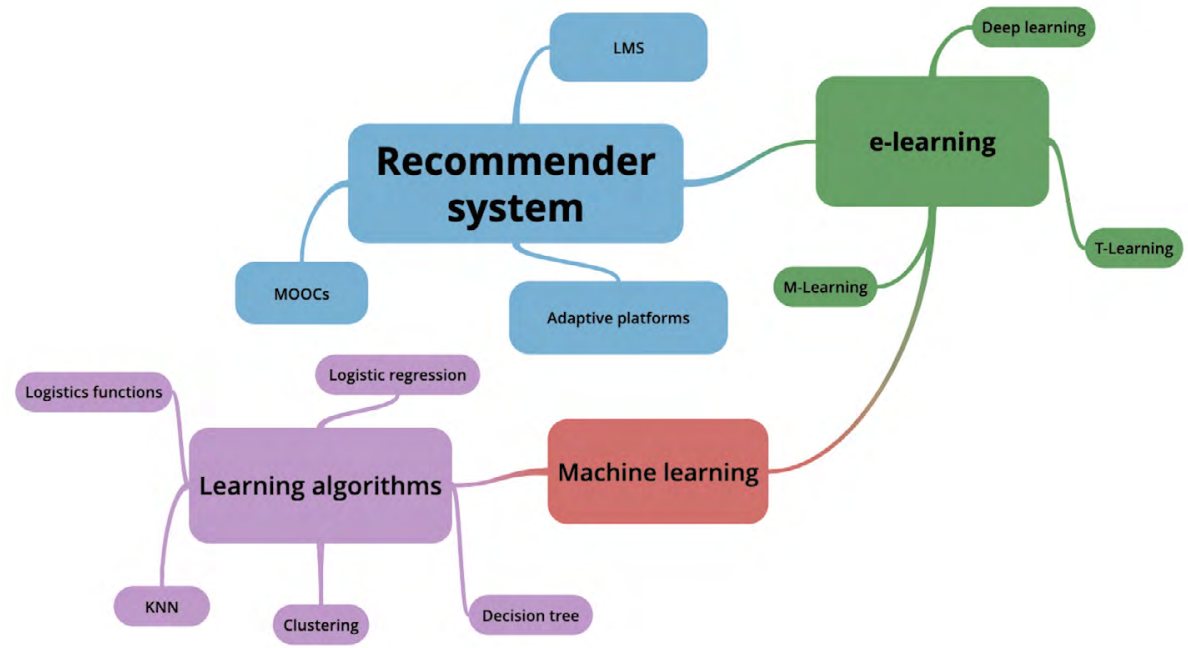

Figure 4. Mental map of keywords.

Source: Own elaboration 


\section{EVALUATION}

Since in the search the most used type of learning is the supervised one, a general evaluation of the most used algorithms within this type is made, these are: K-nearest neighbors (KNN), Naïve Bayes classifier, decision trees and logistic regression.

To perform the general evaluation of the mentioned above, a tool that includes the target algorithms within a larger collection of algorithms is used. For this purpose, the Weka tool is employed, which has the function of classifying supervised learning type algorithms. In this sense, this tool is chosen to perform the evaluation as realized in [24] and [25].

In that way, in order to execute the evaluation, a relevant test data set is searched for. This data set was found on the website UCI - Machine Learning Repository [26]; the data set Student Academics Performance is used. Table 2 presents the results of the evaluation of the algorithms.

Table 2. Evaluation results.

\begin{tabular}{lcccc}
\hline \multicolumn{1}{c}{ Algorithms } & Decision tree J48 & Naive Bayes & Logistics functions & KNN \\
\hline \% Success & $45.8 \%$ & $54.19 \%$ & $46.56 \%$ & $51.9 \%$ \\
Maximum accuracy & 0.530 & 0.667 & 0.613 & 0.578 \\
Recall & 0.625 & 0.750 & 0.679 & 0.857 \\
\hline \multicolumn{4}{c}{ Source: Own elaboration }
\end{tabular}

An example of the results seen from the Weka tool is shown in figure 5 .

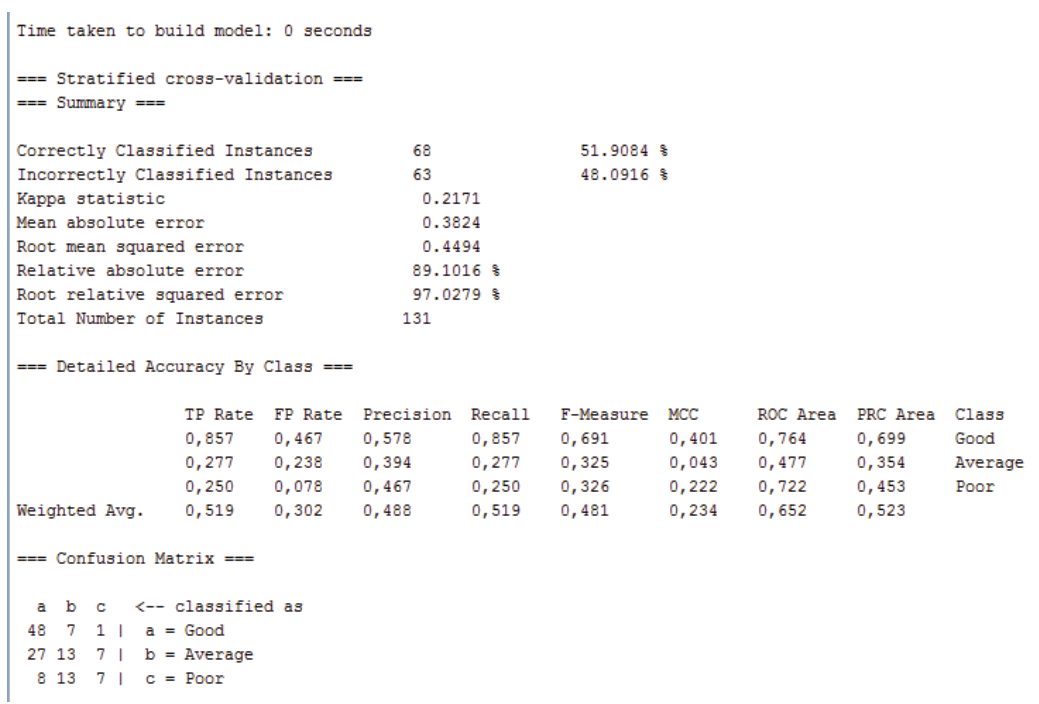

Figure 5. KNN algorithm evaluation results.

Source: Own elaboration 


\section{ANALYSIS}

This research showed that there is a trend in searches for recommendation systems in the context of e-learning, supervised learning algorithms, machine learning and its application in education. Specifically, in the search algorithms, the most used type of learning is the supervised one. The evaluation of these kind of algorithms showed better success rates and maximum accuracy with the Naïve Bayes algorithm, and the best recall with the KNN algorithm, although the performance of the algorithms varies, there are no significant changes in the percentage success and maximum precision while the recall has a greater variation being the best results with the KNN and the Naïve Bayes in that order, among the evaluated algorithms.

\section{CONCLUSIONS}

The results obtained in the search show a need and a large commercial gap in Colombia to investigate, design and implement adaptive platforms that generate recommendations to enhance the education sector in terms of improving the process of teaching and learning through ICTs. On the other hand, determining learning styles and taking them into account in e-learning systems have become the fundamental basis for developing an efficient learning path for students; in addition, the level of knowledge and the pace of work of each student are important when generating recommendations.

Up to now, one of the most notable barriers to the incorporation of intelligent, distance, e-learning or MOOCS tutoring systems is the lack of awareness about the internet connection or the devices and tools through which students' study outside or inside the classroom. It is important to highlight that during the search no significant articles were found that consider the above aspects and that mention them as barriers. Some of the techniques and algorithms most commonly used in the field of platforms or adaptive and recommendation systems are: Naïve Bayes, genetic algorithms, neural networks, fuzzy logic and multi-criteria collaborative filters. In this sense, it is evident that the technique most used for the construction of this kind of systems is supervised learning within automatic learning.

\section{ACKNOWLEDGEMENTS}

This article has received the support of the Cluster CreaTIC Technological Development Center, offering advice and tutoring in all the topics related here, co-financed by the Joven investigador - 2018 agreement celebrated between the University of Cauca with the Innovacción project and the Cluster CreaTIC Corporation. 


\section{REFERENCES}

[1] M. S. Ramírez-Montoya and F. J. García-Peñalvo, "Presentación. La integración efectiva del dispositivo móvil en la educación y en el aprendizaje," RIED. Rev. Iberoam. Educ. a Distancia, vol. 20, 2, p. 29, 2017. DOI: http://dx.doi.org/10.6018/red/52/1

[2] R. Avello Martínez and J. M. Duart, "Nuevas tendencias de aprendizaje colaborativo en e-learning: Claves para su implementación efectiva," Estud. pedagógicos, vol. 42, 1, pp. 271-282, 2016. DOI: http://dx.doi.org/10.4067/S0718-07052016000100017

[3] K. Schwab, "El surgimiento de nuevas tecnologías - Archivo Digital de Noticias de Colombia y el Mundo desde 1.990 - eltiempo.com,” 2016. [Online]. Available: https://www.eltiempo. com/archivo/documento/CMS-16759801. [Accessed: 22-Feb-2019].

[4] Y. Ramírez León, "Presentación de contenidos en entornos educativos virtuales basada en la adaptación a los estilos de aprendizaje," Etic@Net, vol. 11, 1695-324X, pp. 306-321, 2011.

[5] M. I. Jordan and T. M. Mitchell, "Machine learning: Trends, perspectives, and prospects.," Science, vol. 349, 6245, pp. 255-60, 2015. DOI: 10.1126/science.aaa8415

[6] V. Sanchez-anguix, R. Chalumuri, and V. Julian, "A multi-objective evolutionary proposal for matching students to supervisors," vol. 800, pp. 94-102, 2019. DOI: https://doi. org/10.1007/978-3-319-94649-8 12

[7] S. K. Howard, J. Ma, and J. Yang, "Student rules: Exploring patterns of students' computerefficacy and engagement with digital technologies in learning," Comput. Educ., vol. 101, pp. 29-42, 2016. DOI: 10.1016/j.compedu.2016.05.008

[8] C. K. Pereira, F. Campos, V. Ströele, J. M. N. David, and R. Braga, "BROAD-RSI - educationalrecommendersystemusing social networksinteractions and linked data," J. Internet Serv. Appl., vol. 9, 1, 2018. DOI: https://doi.org/10.1186/s13174-018-0076-5

[9] M. Birjali, A. Beni-Hssane, and M. Erritali, "A novel adaptive e-learning model based on Big Data by using competence-based knowledge and social learner activities," Appl. SoftComput. $J .$, vol. 69, pp. 14-32, 2018. DOI: 10.1016/j.asoc.2018.04.030

[10] M. Tahmasebi, F. FotouhiGhazvini, and M. Esmaeili, "Implementation and Evaluation of a Resource-Based Learning Recommender Based on Learning Style and Web Page Features," J. Web Eng., vol. 17, 4, pp. 284-304, 2018.

[11] V. Bradac and B. Walek, "A comprehensive adaptive system for e-learning of foreign languages,” ExpertSyst. Appl., vol. 90, pp. 414-426, Dec. 2017. DOI: https://doi.org/10.1016/j. eswa.2017.08.019

[12] P. K. Udupi, P. Malali, and H. Noronha, "Big data integration for transition from e-learning to smart learning framework," 2016 3rd MEC Int. Conf. Big Data Smart City, 2016. 
[13] N. D. H. Cuong, N. Arch-Int, and S. Arch-Int, "FUSE: A Fuzzy-Semantic Framework for Personalizing Learning Recommendations," Int. J. Inf. Technol. Decis. Mak., vol. 17, 04, pp. 1173-1201, 2018. DOI: https://doi.org/10.1142/S0219622018500220

[14] K. Takaoka, K. Yamazaki, E. Sakurai, K. Yamashita, and Y. Motomura, "Development of an integrated AI platform and an ecosystem for daily life, business and social problems," Adv. Intell. Syst. Comput., vol. 787, pp. 300-309, 2019. DOI: https://doi.org/10.1007/978-3-319-94229-2_29

[15] V. Kant, T. Jhalani, and P. Dwivedi, "Enhanced multi-criteria recommender system based on fuzzy Bayesian approach,” Multimed. Tools Appl., vol. 77, no. 10, pp. 12935-12953, 2018. DOI: https://doi.org/10.1007/s11042-017-4924-2

[16] M. B. Lopez, A. J. H. Montes, R. V. Ramirez, and G. A. Hernandez, "EmoRemSys: Sistema de recomendación de recursos educativos basado en detección de emociones," RISTI - Rev. Ibérica Sist. e Tecnol. Informação, 17, Mar. 2016. DOI: 10.17013/RISTI.17.80-95

[17] B. D. Nye, "Intelligent tutoring systems by and for the developing world: A review of trends and approaches for educational technology in a global context," Int. J. Artif. Intell. Educ., vol. 25, 2, pp. 177-203, 2015. DOI: https://doi.org/10.1007/s40593-014-0028-6

[18] A. Klašnja-Milićević, M. Ivanović, B. Vesin, and Z. Budimac, "Enhancing e-learning systems with personalized recommendation based on collaborative tagging techniques," Appl. Intell., vol. 48, 6, pp. 1519-1535, 2018. DOI: https://doi.org/10.1007/s10489-017-1051-8

[19] E. R. Núñez-Valdez, D. Quintana, R. González Crespo, P. Isasi, and E. Herrera-Viedma, “A recommender system based on implicit feedback for selective dissemination of e-books," Inf. Sci. (Ny)., vol. 467, pp. 87-98, 2018. DOI: https://doi.org/10.1016/j.ins.2018.07.068

[20] L. X. Li, S. Soraya, and A. Rahman, "Students' learning style detection using tree augmented naïve Bayes Subject Category: Subject Areas :," R. Soc. Open Sci., 2018. DOI: 10.1098/ rsos. 172108

[21] M. W. Rodrigues, S. Isotani, and L. E. Zárate, "Educational Data Mining: A review of evaluation process in the e-learning," Telemat. Informatics, vol. 35, 6, pp. 1701-1717, 2018. DOI: $10.1016 /$ j.tele.2018.04.015

[22] S. KumarBasak, M. Wotto, and P. Bélanger, "E-learning, M-learning and D-learning: Conceptual definition and comparative analysis," E-Learning Digit. Media, vol. 15, 4, pp. 191-216, 2018. DOI: 10.1177/2042753018785180

[23] S. Assami, N. Daoudi, and R. Ajhoun, "Personalization criteria for enhancing learner engagement in MOOC platforms," IEEE Glob. Eng. Educ. Conf. EDUCON, vol. 2018-April, pp. 1265-1272, 2018. DOI: 10.1109/EDUCON.2018.8363375

[24] O. M. Spositto, M. E. Etcheverry, H. L. Ryckeboer, and J. Bossero, "Aplicación de técnicas de minería de datos para la evaluación del rendimiento académico y la deserción estudiantil," 2008 . 
[25] J. Sujatha and S. P. Rajagopalan, "Performance evaluation of machine learning algorithms in the classification of Parkinson disease using voice attributes," Int. J. Appl. Eng. Res., vol. 12, 21, pp. 10669-10675, 2017.

[26] A. E. S. Carvalho Brito et al., 15th European Concurrent Engineering Conference 2008, ECEC '2008 [and] 5th Future Business Technology Conference, FUBUTEC '2008 : April 9-11, 2008, Porto, Portugal. Eurosis-Eti, 2008. 